\title{
Influence of Harvest Stage and Rootstock Genotype on Compositional and Sensory Profile of the Elongated Tomato cv. "Sir Elyan"
}

\author{
Rosario Paolo Mauro ${ }^{1, *(\mathbb{D}, \text { Valeria Rizzo }}{ }^{1}$, Cherubino Leonardi ${ }^{1}$, Agata Mazzaglia ${ }^{1}$, \\ Giuseppe Muratore ${ }^{1}\left(\mathbb{D}\right.$, Miriam Distefano ${ }^{1}$, Leo Sabatino ${ }^{2} \mathbb{D}$ and Francesco Giuffrida ${ }^{1}$ \\ 1 Dipartimento di Agricoltura, Alimentazione e Ambiente (Di3A), University of Catania, via Valdisavoia 5, \\ 95123 Catania, Italy; vrizzo@unict.it (V.R.); cherubino.leonardi@unict.it (C.L.); \\ agata.mazzaglia@unict.it (A.M.); g.muratore@unict.it (G.M.); miriam.distefano@unict.it (M.D.); \\ francesco.giuffrida@unict.it (F.G.) \\ 2 Dipartimento di Scienze Agrarie, Alimentari e Forestali (SAAF), University of Palermo, viale delle Scienze \\ Ed. 4, 90128 Palermo, Italy; leo.sabatino@unipa.it \\ * Correspondence: rosario.mauro@unict.it; Tel.: +39-095-4783314
}

Received: 5 February 2020; Accepted: 12 March 2020; Published: 16 March 2020

\begin{abstract}
The present experiment addressed the effects of two harvest stages, namely breaker $\left(\mathrm{S}_{1}\right)$ and turning $\left(\mathrm{S}_{2}\right)$, on compositional and sensory profile of grafted, greenhouse elongated tomatoes cv. "Sir Elyan". The rootstocks "He-Man", "Interpro", and "Armstrong" were used. The $\mathrm{S}_{1}$ fruits showed a higher dry matter content, firmness and titratable acidity when compared to the $S_{2}$ ones (by $6 \%, 3 \%$, and $15 \%$, respectively). They showed, also, the highest L-ascorbic acid concentration and antioxidant activity. Differently, soluble solid content, lycopene and $\beta$-carotene increased in the $\mathrm{S}_{2}$ fruits (by $4 \%, 92 \%$, and $26 \%$, respectively). Excepting methyl salicylate, all the volatiles detected peaked in the $S_{2}$ fruits, which were scored by panelists as sweeter and more flavorful than the $S_{1}$ ones. Among the rootstock genotypes, "He-Man" promoted fruits firmness, carotenoids concentration and antioxidant activity, irrespective of the harvest stage. "Interpro" enhanced the sensory attributes of the $S_{1}$ fruits in terms of bitterness, sourness, sweetness and flavor. Differently, sweetness, sourness, and tomato flavor of the $S_{2}$ fruits were promoted by "Armstrong". The results highlight the influence of rootstock genotype on the nutraceutical and sensorial profile of "Sir Elyan" fruits harvested at early ripening stages.
\end{abstract}

Keywords: Solanum lycopersicum L.; fruit ripening; grafting; nutraceutical profile; volatile composition

\section{Introduction}

In the Mediterranean Basin, tomato (Solanum lycopersicum L.) represents a resource of primary economic and dietary importance [1]. Where quality is concerned, organoleptic traits and health-promoting compounds of fresh vegetables are becoming increasingly important [2,3], and for tomato these characteristics nowadays play a pivotal role in influencing consumers' preferences. From a nutraceutical viewpoint, tomato is a primary source of antioxidant in the human diet, with ascorbic acid, lycopene, and $\beta$-carotene being among the most effective in protecting human health from several degenerative diseases [4].

Tomato flavor results from the interaction among taste (deriving from sugars and organic acids) and aroma [5]. Tomato aroma flows from over 400 volatile organic compounds (VOCs), although only few of them are reputed of primary importance [5,6]. It has been demonstrated that these traits involve the developmentally-regulated expression of many polygenic systems, making them strongly influenced by environmental and agronomic factors [6]. Nowadays, greenhouse tomato 
cultivations are strongly dependent on the adoption of grafting, in order to increase their yield and resistance to biotic and/or abiotic stressors [7-9]. It has been reported that tomato quality variables such as acidity, sugar, flavor, aroma, color, carotenoid content, and texture can be differently influenced by the rootstock-scion combinations, also because of their interaction with external factors such as climate conditions and cultural practices [10]. Tomato fruits are harvested at different ripening stages, according to its destination. Fruit destined for the fresh market can be harvested from the mature-green to fully ripe stage [11], according to the consumers' demand and fruit typology.

In the paste decades, breeding has prioritized yield, shelf-life, and diseases resistance, which may have contributed to compromise flavor characteristics in fresh market tomatoes. However, the lack of flavor of retail tomatoes is partly due also to harvesting fruits before their full ripening is achieved. In fact, the concentration of individual volatiles in tomato fruits depends by the ripening stage at harvest, and fruit harvested before full ripening usually do not produce the characteristic volatiles associated to high quality tomatoes [11]. However, the threshold concentrations detected by humans for various aroma compounds range over many orders of magnitude. Sensory observations could be used to confirm the contribution of these compounds to odor and aroma [12].

The elongated-type tomato, that represents a significant commercial niche in Italy, could be consumed at breaker or turning stage. In a survey in Italy, the first ripening stages are preferred by the $20 \%$ of fresh tomato consumers [13].

The objective of this work was to investigate the composition and sensorial properties of tomato harvested at breaker and turning stages of an elongated tomato cultivar, grafted onto three common rootstocks in Mediterranean greenhouse cultivation.

\section{Materials and Methods}

\subsection{Experimental Materials and Growth Conditions}

The experiment was conducted in a $2400 \mathrm{~m}^{2}$ greenhouse located in Southwest Sicily $\left(36^{\circ} 50^{\prime} \mathrm{N}\right.$, $14^{\circ} 28^{\prime} \mathrm{E} ; 18 \mathrm{~m}$ a.s.l.). Tomato plants $\mathrm{cv}$. "Sir Elyan" $\mathrm{F}_{1}$, belonging to the medium-sized, elongated type, were grafted onto 3 rootstocks, characterized by different ability to imprint vegetative vigor to the scion: "He-Man" $F_{1}$ (low-vigor) "Interpro" $F_{1}$ (medium-vigor), and "Armstrong" $F_{1}$ (high-vigor). Transplanting was effected at the end of January adopting the following distances: $1.20 \mathrm{~m}$ (between double rows), $0.80 \mathrm{~m}$ (between paired rows) and $0.70 \mathrm{~m}$ (within single rows) (1.43 plant $\mathrm{m}^{-2}$, 2 stems plant $^{-1}$ ). A typical fertilization program was applied, whereas drip irrigation was provided when accumulated daily evaporation reached $25 \mathrm{~mm}$. The crop was grown up to the half of July. A two-way randomized blocks design with four replications was adopted, using $6.8 \times 3.6 \mathrm{~m}$ experimental plots, each containing 16 plants (net of borders).

\subsection{Carpometric Determinations}

On 10 May, 32 commercial tomato fruits from the third trusses per replicate were hand-harvested at 2 different ripening stages. These were breaker stage (16 fruits per replicate), i.e., when the berries started turning to red by their stylar end (rank 3 of the OECD Tomato Colour Gauge, hereafter $\mathrm{S}_{1}$ ); turning stage (16 fruits per replicate), i.e., when colour change regarded $~ 30$ of the esocarp (rank 4 of OECD Tomato Colour Gauge, hereafter $\mathrm{S}_{2}$ ). Soon after harvest, fruits were transported in the laboratory and processed for further analysis. Fruits fresh weight was determined, whereas the fruit shape index was calculated as the ratio among longitudinal and transversal diameters. Fruit firmness was determined through a Digital Texture Analyser mod. TA-XT2 (Stable Micro Systems, Godalming, $\mathrm{UK}$ ) and defined as the force (N) needed to impress a $2 \mathrm{~mm}$ fruit deformation along its equatorial axis. Subsamples of collected fruits were kept in a thermo-ventilated oven at $70^{\circ} \mathrm{C}$ (Binder, Milan, Italy) until constant weight was reached, in order to determine their dry matter content. 


\subsection{Fruit Quality Determinations}

Subsamples of harvested fruit were washed with demineralized water, dried with paper and blended with a domestic food processor at room temperature. The resulting puree was centrifuged and an aliquot of the supernatant was used to determine the soluble solids content (SSC) by using a digital refractometer DBX-55A (Atago Co., Ltd., Tokyo, Japan) provided with an automatic temperature compensation system. Titratable acidity (TA) was determined using $10 \mathrm{~g}$ aliquots of tomato fruits poured in $50 \mathrm{~mL}$ of distilled water and titrated with $0.1 \mathrm{~N} \mathrm{NaOH}$ to an end-point of $\mathrm{pH}$ 8.1. TA was expressed as $\mathrm{g} \mathrm{L}^{-1}$ citric acid (CA). The SSC/TA ratio was also calculated. Lycopene and $\beta$-carotene were extracted using the method described by Sharma and Le Maguer [14] and quantified by HPLC (equipped with a C30 Acclaim column) according to Gregory et al. [15] and Subagio et al. [16]. Ascorbic acid was extracted and quantified by HPLC (with an Ultra AQ C18 column) according to Nisperos-Carriedo et al. [17]. The antioxidant activity was determined using the free radical 2,2-diphenyl-1-picrylhydrazyl (DPPH) assay, according to Brand-Williams et al. [18].

\subsection{Volatile Extraction and Analysis}

Soon after harvest, fresh tomato sample were chopped and mixed. The aroma compounds identification was performed using SPME coupled with GC/MS. The fiber was chosen according to Beltran et al. [19], i.e., a $75 \mu \mathrm{m}$ Carboxen/PDMS (CAR/PDMS) fiber (Supelco, Bellefonte, PA, USA). Before use, the fiber was preconditioned in the GC injection port at $30{ }^{\circ} \mathrm{C}$ for $1 \mathrm{~h}$, then exposed for $1 \mathrm{~h}$ to the headspace of a $25 \mathrm{~mL}$ septum-sealed glass vial containing $20 \mathrm{~g}$ aliquot of homogenized fresh tomato. Each vial was previously immersed in a bath water at $60^{\circ} \mathrm{C}$ for $15 \mathrm{~min}$. GC-MS analyses were performed using an Agilent (Palo Alto, CA, USA) 6890 N GC equipped with a $30 \mathrm{~cm}$ length, $0.20 \mathrm{~mm}$ i.d., $0.20 \mu \mathrm{m}$ film thickness, fused silica capillary column (SUPELCOWAX' ${ }^{\mathrm{TM}} 10$, Supelco). During the analysis, the GC injection port temperature was $250{ }^{\circ} \mathrm{C}$, with a split ratio of 5:1. Helium was used as the carrier gas at a flow rate of $1.1 \mathrm{~mL} \mathrm{~min}^{-1}$. The column temperature was held at $40^{\circ} \mathrm{C}$ for $5 \mathrm{~min}$, then programmed to increase by $5^{\circ} \mathrm{C} \mathrm{min}^{-1}$ to $220^{\circ} \mathrm{C}$, which was held for $10 \mathrm{~min}$. Mass spectrometry conditions were as follows: ion source, $230^{\circ} \mathrm{C}$; electron energy, $70 \mathrm{eV}$; multiplier voltage, $1247 \mathrm{~V}$; GC/MS interface zone, $280^{\circ} \mathrm{C}$; and a scan range of 35-350 mass units. Duplicate analyses were performed for each sample. Identification of the compounds was carried out by comparison of the analytes fragmentation patterns with the spectra libraries (NIST 98, US).

\subsection{Sensory Analysis}

The UNI EN ISO 13299:2016 [20] sensory profile method was used to measure any difference in sensory characteristics of tomatoes. Twelve trained (ISO 8586:2012) [21] panelists (six females and six males, 28-40 years old) with a broad expertise in vegetables were trained in 3 sessions, using both commercial and experimental samples to familiarize with scales and procedures. The panelists, using a discontinuous scale between 1 (absence of sensation) and 9 (extremely intense), evaluated the intensity of the sixteen attributes selected on the basis of frequency ( $\geq 60 \%)$ : 1 for appearance (freshness); 1 for tactile hand feel (firmness); 3 for odor (herbaceous, tomato and off odors), 3 for flavor (herbaceous, tomato and off-flavors); 4 for taste (salt, sour, sweet and bitter); 4 for rheological properties (crunchy, juicy, mealy, peel thick) (Table 1). The evaluation sessions were conducted in the sensory laboratory (UNI EN ISO 8589:2014) [22] of Di3A (University of Catania) from 11:00 a.m. to 12:00 a.m. in individual booths illuminated with a white light. Tomato samples were served on plates, coded with three-digit numbers and water was provided to panelists for rinsing between samples. The order presentation was randomized among panelists and sessions. All data were acquired by a direct computerized registration system (FIZZ Byosistemes. ver. 2.00 M, Couternon, France). 
Table 1. List of evaluated sensory attributes and their definitions.

\begin{tabular}{|c|c|}
\hline Attribute & Description \\
\hline Freshness & Degree of freshness of the product by visual estimation \\
\hline Firmness & Strength required to compress a food between the moles \\
\hline Tomato odor & Characteristics odor of tomato perceived with the sense of smell \\
\hline Herbaceous odor & Characteristics odor of herbaceous perceived with the sense of smell \\
\hline Off-odor & $\begin{array}{c}\text { Unpleasant odor not characteristic of the product concerned, perceived through } \\
\text { the sense of smell }\end{array}$ \\
\hline Salt & $\begin{array}{l}\text { One of the four basic tastes caused by aqueous solutions of salt compounds } \\
\text { perceived on the tongue }\end{array}$ \\
\hline Sour & $\begin{array}{c}\text { One of the four basic tastes caused by aqueous solutions of acid compounds } \\
\text { perceived on the tongue }\end{array}$ \\
\hline Sweet & $\begin{array}{c}\text { One of the four basic tastes caused by aqueous solutions of sweet compounds } \\
\text { perceived on the tongue }\end{array}$ \\
\hline Bitter & $\begin{array}{c}\text { One of the four basic tastes caused by aqueous solutions of bitter compounds } \\
\text { perceived on the tongue }\end{array}$ \\
\hline Crunchy & The sensation of muffled grinding of a foodstuff \\
\hline Juicy & The amount of liquid released from the samples during first and second chew \\
\hline Mealy & The amount of small particles perceived in the mouth when biting the sample \\
\hline Peel thick & Resistance of the epicarp to removal \\
\hline Tomato flavor & $\begin{array}{c}\text { Characteristic flavor of tomato perceived by the sense of smell and mouth with } \\
\text { the swallowing }\end{array}$ \\
\hline Herbaceous flavor & $\begin{array}{c}\text { Characteristic flavor of herbaceous perceived by the sense of smell and mouth } \\
\text { with the swallowing }\end{array}$ \\
\hline Off-flavor & $\begin{array}{l}\text { Unpleasant flavor not characteristic of the product concerned, perceived by the } \\
\text { sense of smell and mouth with the swallowing }\end{array}$ \\
\hline
\end{tabular}

\subsection{Statistical Procedures}

Collected and calculated data attributable to ratio scales were firstly subjected to Shapiro-Wilk and Levene's test, in order to check for normal distribution and homoscedasticity, respectively, then to a factorial "rootstock $\times$ ripening stage" $(\mathrm{R} \times \mathrm{S}$ ) analysis of variance (ANOVA), according to the experimental layout adopted in the greenhouse. Percentage data were Bliss' transformed before the ANOVA (untransformed data are reported and discussed), whereas multiple mean comparisons were performed through Fisher's protected LSD test $(p=0.05)$. Sensory data were subjected to a two-way non-parametric ANOVA using Friedman's test followed by the calculation of Kendall's coefficient of concordance, in order to check the independence of observations. Means separation was performed in all pairwise comparisons by using the Mann-Whitney's U-test, with an associated $P$-level calculated according to the Bonferroni's correction. A correlation analysis was also performed, in order to define possible relationships among volatiles concentration and sensory scores. All calculations were performed using Excel version 2016 (Microsoft Corporation, Redmond, WA, USA) and Minitab version 16.1.1 (Minitab Inc., State College, PA, USA).

\section{Results}

\subsection{Carpometric Traits}

Average fruit weight and fruit shape index were both affected by $\mathrm{R} \times \mathrm{S}$ interaction. Passing from $\mathrm{S}_{1}$ to $S_{2}$, the former variable significantly increased only in "Sir Elyan" grafted onto "Interpro" $(+13.6 \%)$, whereas shape index decreased only in "Sir Elyan" grafted onto "Armstrong" (-5.3\%) (Table 2). Fruit dry matter showed a similar trend in all the grafting combinations, decreasing from $7.4\left(\mathrm{~S}_{1}\right)$ to $7.0 \%$ $\left(\mathrm{S}_{2}\right)$, whereas fruit firmness proved to be higher in "Sir Elyan" grafted onto "He-Man" than onto the other rootstocks, and in $S_{1}$ than $S_{2}$ stage (Table 2). 
Table 2. Carpometric traits of tomatoes "Sir Elyan" as affected by rootstock and ripening stage (mean \pm standard error). Different letters among factor means (bold numbers) indicate significance at Fisher's LSD test $(p=0.05)$. NS: not significant.

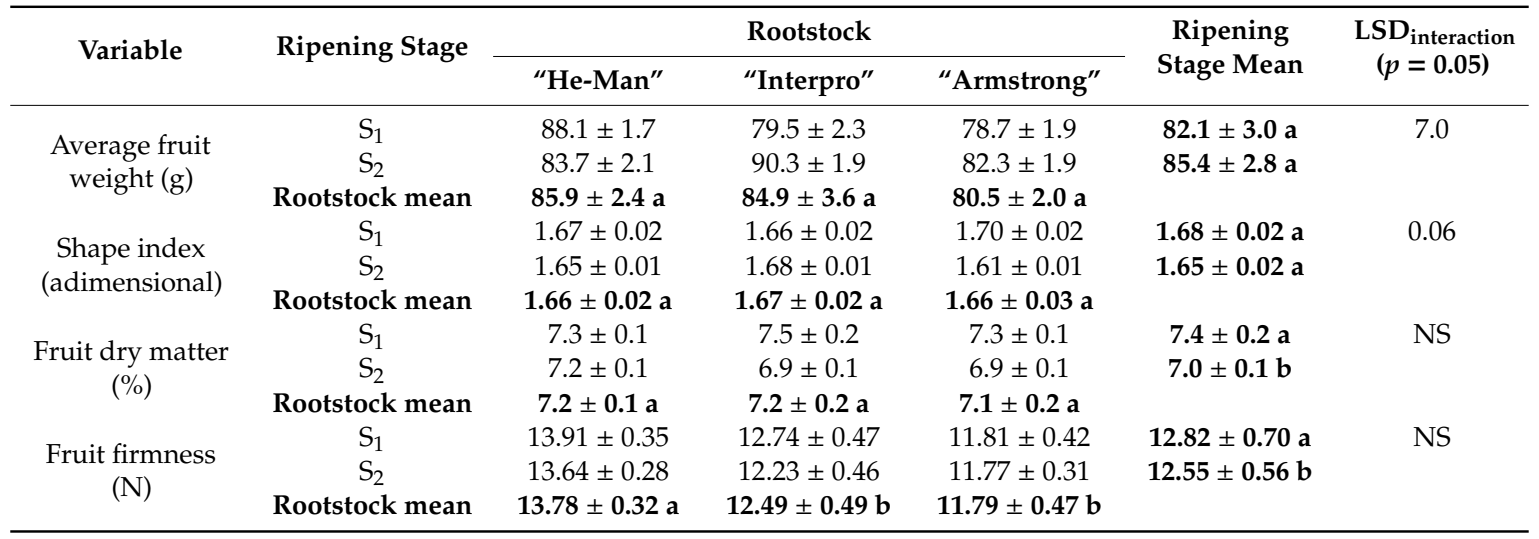

\subsection{Taste Variables}

Soluble solid content (SSC) proved to be significantly higher in $S_{2}$ than in $S_{1}$ fruits, and when "Sir Elyan" was grafted onto "Interpro" (Table 3). Differently, a significant R $\times$ S interaction was recorded for titratable acidity (TA) since, passing from $S_{1}$ to $S_{2}$, it significantly decreased in "Sir Elyan" grafted onto "Interpro" and "Armstrong" (-19.7\% and -12.8\%, respectively) and did not change using "He-Man" as rootstock (Table 3). Both main factors significantly affected the SSC/TA ratio, as in $\mathrm{S}_{2}$ fruits it was $18.7 \%$ higher than the $S_{1}$ ones, showing also a higher value in "Sir Elyan" grafted onto "He-Man" (Table 3).

Table 3. Soluble solid content (SSC), titratable acidity (TA) and their ratio in tomatoes "Sir Elyan" as affected by rootstock and ripening stage (mean \pm standard error). Different letters among factor means (bold numbers) indicate significance at Fisher's LSD test $(p=0.05)$. NS: not significant.

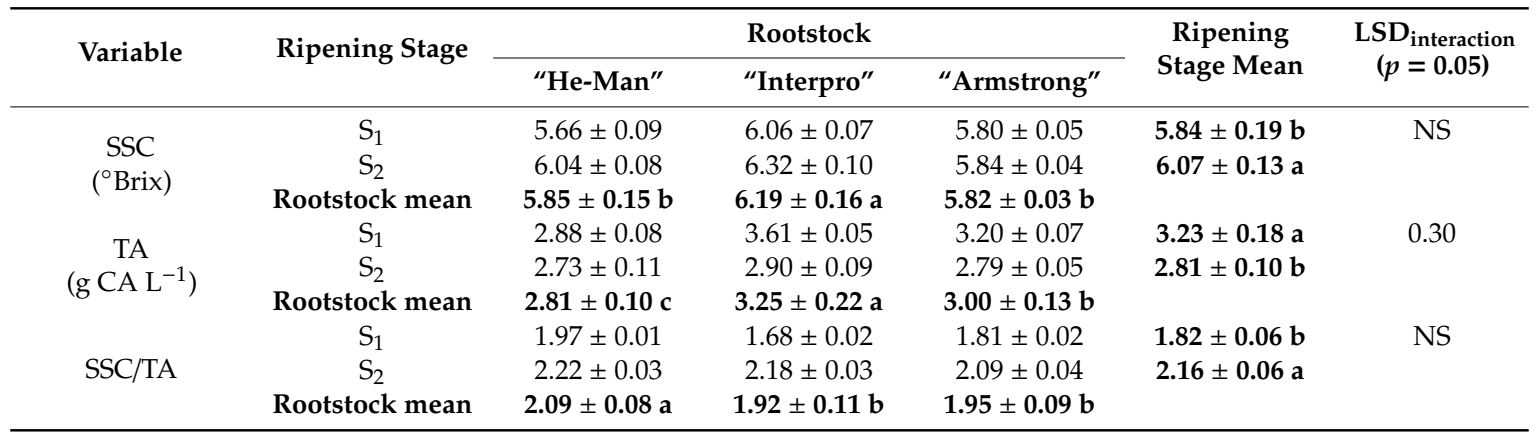

\subsection{Fruit Nutraceutical Profile}

As regards the L-ascorbic acid content, the $S_{2}$ fruits showed a significant decrease when "Sir Elyan" was grafted onto "He-Man" (-21.4\%) while for the other rootstocks no statistical variations among ripening stages were recorded (Table 4). On the average of grafting combinations, lycopene content increased by $91.5 \%$ passing from $S_{1}$ to $S_{2}$, whereas showed significantly lower values in "Sir Elyan" grafted onto "Armstrong", and the highest content in "Sir Elyan" grafted onto "He-Man" (Table 4). The $\beta$-carotene content was affected by $\mathrm{R} \times \mathrm{S}$ interaction since, passing from $\mathrm{S}_{1}$ to $\mathrm{S}_{2}$, the higher increase was noticed in the grafting combination "Sir Elyan"/ "Armstrong" than in the other ones (Table 4). DPPH significantly decreased passing from $S_{1}$ to $S_{2}$ using "Interpro" and "Armstrong" rootstocks (Table 4$)$. 
Table 4. L-ascorbic acid, main carotenoids content and antioxidant activity in tomatoes "Sir Elyan" as affected by rootstock and ripening stage (mean \pm standard error). Different letters among factor means (bold numbers) indicate significance at Fisher's LSD test $(p=0.05)$. NS: not significant.

\begin{tabular}{|c|c|c|c|c|c|c|}
\hline \multirow{2}{*}{ Variable } & \multirow{2}{*}{ Ripening Stage } & \multicolumn{3}{|c|}{ Rootstock } & \multirow{2}{*}{$\begin{array}{c}\text { Ripening } \\
\text { Stage Mean }\end{array}$} & \multirow{2}{*}{$\begin{array}{l}\text { LSD }_{\text {interaction }} \\
\quad(p=0.05)\end{array}$} \\
\hline & & “He-Man" & "Interpro" & "Armstrong" & & \\
\hline \multirow{3}{*}{$\begin{array}{c}\mathrm{L}-\text { ascorbic acid } \\
\left(\mu \mathrm{g} \mathrm{g}^{-1} \mathrm{FW}\right)\end{array}$} & $\mathrm{S}_{1}$ & $126 \pm 4$ & $103 \pm 3$ & $97 \pm 4$ & $109 \pm 8$ a & \multirow[t]{3}{*}{14} \\
\hline & $\mathrm{S}_{2}$ & $99 \pm 3$ & $100 \pm 5$ & $91 \pm 3$ & $97 \pm 5 b$ & \\
\hline & Rootstock mean & $113 \pm 9 a$ & $102 \pm 4 b$ & $94 \pm 4 b$ & & \\
\hline \multirow{3}{*}{$\begin{array}{l}\text { Lycopene } \\
\left(\mu \mathrm{g} \mathrm{g}^{-1} \mathrm{FW}\right)\end{array}$} & $\mathrm{S}_{1}$ & $8.3 \pm 0.3$ & $7.1 \pm 0.3$ & $5.9 \pm 0.2$ & $7.1 \pm 0.6 b$ & \multirow[t]{3}{*}{ NS } \\
\hline & $\mathrm{S}_{2}$ & $15.3 \pm 0.5$ & $13.0 \pm 0.6$ & $12.4 \pm 0.3$ & $13.6 \pm 0.9 \mathrm{a}$ & \\
\hline & Rootstock mean & $11.8 \pm 2.3 \mathrm{a}$ & $10.1 \pm 1.6 \mathrm{~b}$ & $9.2 \pm 1.9 \mathrm{c}$ & & \\
\hline \multirow{3}{*}{$\begin{array}{l}\beta-\text { carotene } \\
\left(\mu \mathrm{g} \mathrm{g}^{-1} \mathrm{FW}\right)\end{array}$} & $\mathrm{S}_{1}$ & $9.5 \pm 0.3$ & $6.6 \pm 0.4$ & $7.9 \pm 0.2$ & $8.0 \pm 0.6 b$ & \multirow[t]{3}{*}{1.6} \\
\hline & $\mathrm{S}_{2}$ & $11.4 \pm 0.5$ & $8.5 \pm 0.6$ & $10.1 \pm 0.3$ & $10.1 \pm 0.9 \mathrm{a}$ & \\
\hline & Rootstock mean & $10.5 \pm 0.6 \mathrm{a}$ & $7.6 \pm 0.8 \mathrm{c}$ & $9.0 \pm 1.0 \mathrm{~b}$ & & \\
\hline DPPH & $\mathrm{S}_{1}$ & $1.90 \pm 0.08$ & $1.84 \pm 0.06$ & $1.67 \pm 0.06$ & $1.80 \pm 0.18 \mathrm{a}$ & \multirow[t]{3}{*}{0.13} \\
\hline$\left(\mu \mathrm{mol}\right.$ TEAC $\mathrm{g}^{-1}$ & $\mathrm{S}_{2}$ & $1.82 \pm 0.06$ & $1.44 \pm 0.04$ & $1.05 \pm 0.04$ & $1.44 \pm 0.13 b$ & \\
\hline FW) & Rootstock mean & $1.86 \pm 0.12 \mathrm{a}$ & $1.64 \pm 0.16 b$ & $1.36 \pm 0.2 c$ & & \\
\hline
\end{tabular}

\subsection{Fruit Volatile Profile}

Twelve volatile compounds, which were suggested to be key tomato aroma contributors [23], were identified in our study, including 4 alcohols (3-methyl-1-butanol, 1-pentanol, 1-hexanol, and 3-henex-1-ol), 5 aldehydes (3-methylbutanal, hexanal, E-2-hexenal, E-2-heptenal and octanal), plus the apocarotenoids $\beta$-ionone and 6-methyl-5-hepten-2-one and the ester methyl salicylate (Table 5). Excepting methyl salicylate, the average concentration of all detected volatiles was higher in the $\mathrm{S}_{2}$ fruits (Table 5), but all these differences were rootstock-dependent. Among the alcohols volatiles, 3-methyl-1-butanol concentration increased in "Sir Elyan" grafted onto "Interpro" and "Armstrong" (+2.3 and 24.2-fold, respectively, passing from $S_{1}$ to $S_{2}$ ) and decreased when grafted onto "He-Man". "He-Man" and "Armstrong" determined a higher rise in 1-pentanol (+2.6 and 1.5-fold, respectively) than "Interpro". "He-Man" caused also the highest rise in 1-hexanol (+1.6-fold) and in 3-hexen-1-ol concentration (+1.2-fold) (Figure 1). Considering the aldehydes volatiles, "Armstrong" determined, in the $S_{2}$ fruits, the strongest increase in 3-methylbutanal (+1.1-fold), "Interpro" in hexanal (+16.7-fold) and "He-Man" proved the most marked increase in E-2-hexenal (+4.3-fold), E-2-heptenal (+37.7-fold) and octanal (+5.3-fold) (Figures 2 and 3). Octanal significantly decreased in fruit harvested at $S_{2}$ when grafted onto "Interpro" (Figure 3). Among the remaining compounds, $\beta$-ionone displayed the highest increase in the $S_{2}$ fruits in "Sir Elyan" grafted onto "He-Man" (+2.1-fold), whereas 6-methyl-5-hepten-2-one proved the highest rise on "He-Man" and "Interpro" (+116.5 and 49-fold, respectively) (Figure 3). Methyl salicylate concentration peaked in the $S_{1}$ fruits that, compared to the $S_{2}$ ones, proved the highest concentration in the grafting combination "Sir Elyan"|"Armstrong" (+0.4-fold) (Figure 3). 
Table 5. Peak area $\left(\times 10^{6}\right)$ of volatile organic compounds detected in tomatoes "Sir Elyan", as affected by rootstock and ripening stage (main effects) (mean \pm standard error). Different letters among factor's means indicate significance at Fisher's LSD test ( $p=0.05)$.

\begin{tabular}{|c|c|c|c|c|c|c|c|}
\hline \multirow{2}{*}{ Compound } & \multicolumn{3}{|c|}{ Rootstock } & \multicolumn{2}{|c|}{ Ripening Stage } & \multirow{2}{*}{ Overall Mean } & \multirow{2}{*}{$\begin{array}{c}\text { Odor Description } \\
{[24,25]}\end{array}$} \\
\hline & "He-Man" & "Interpro" & "Armstrong" & $\mathrm{S}_{1}$ & $\mathrm{~S}_{2}$ & & \\
\hline \multicolumn{8}{|l|}{ Alcohols } \\
\hline 3-methyl-1-butanol & $118.6 \pm 24.5 \mathrm{c}$ & $336.1 \pm 81.1 \mathrm{~b}$ & $559.7 \pm 118.5 \mathrm{a}$ & $124.0 \pm 25.4 \mathrm{~b}$ & $552.3 \pm 80.3 \mathrm{a}$ & $338.1 \pm 154.0$ & Whiskey, malt, burnt \\
\hline 1-pentanol & $24.8 \pm 6.3 b$ & $14.2 \pm 2.9 \mathrm{c}$ & $26.6 \pm 5.2 \mathrm{a}$ & $12.0 \pm 1.5 \mathrm{~b}$ & $31.8 \pm 4.2 \mathrm{a}$ & $21.9 \pm 5.1$ & Green \\
\hline 1-hexanol & $29.9 \pm 5.9 \mathrm{~b}$ & $8.0 \pm 1.0 \mathrm{c}$ & $36.3 \pm 2.9 \mathrm{a}$ & $17.7 \pm 4.4 \mathrm{~b}$ & $31.8 \pm 6.7 \mathrm{a}$ & $24.7 \pm 6.2$ & Flower, green \\
\hline $\begin{array}{l}\text { 3-hexen-1-ol } \\
\text { Aldehydes }\end{array}$ & $22.3 \pm 4.8 \mathrm{~b}$ & $49.7 \pm 2.8 \mathrm{a}$ & $15.9 \pm 2.7 \mathrm{c}$ & $24.3 \pm 6.9 \mathrm{~b}$ & $34.3 \pm 6.1 \mathrm{a}$ & $29.3 \pm 6.6$ & Herbal, green \\
\hline 3-methylbutanal & $9.9 \pm 1.5 \mathrm{c}$ & $19.6 \pm 2.7 \mathrm{~b}$ & $50.0 \pm 8.1 \mathrm{a}$ & $20.6 \pm 4.2 \mathrm{~b}$ & $32.4 \pm 5.0 \mathrm{a}$ & $26.5 \pm 8.4$ & Malt \\
\hline Hexanal & $635.3 \pm 69.0 \mathrm{a}$ & $527.2 \pm 91.5 b$ & $556.3 \pm 47.9 \mathrm{ab}$ & $379.5 \pm 74.2 b$ & $766.4 \pm 74.3 \mathrm{a}$ & $572.9 \pm 119.6$ & Grass, tallow, fat \\
\hline E-2-hexenal & $600.8 \pm 84.2 \mathrm{a}$ & $227.7 \pm 55.2 b$ & $111.0 \pm 19.9 \mathrm{c}$ & $144.2 \pm 24.2 \mathrm{~b}$ & $482.1 \pm 64.1 \mathrm{a}$ & $331.2 \pm 134.1$ & Green, apple \\
\hline E-2-heptenal & $106.6 \pm 15.5 \mathrm{a}$ & $23.3 \pm 2.9 c$ & $89.5 \pm 5.2 \mathrm{~b}$ & $37.3 \pm 13.5 \mathrm{~b}$ & $108.9 \pm 23.6 \mathrm{a}$ & $73.1 \pm 29.1$ & Soap, fat, almond \\
\hline $\begin{array}{l}\text { Octanal } \\
\text { Others }\end{array}$ & $395.0 \pm 49.4 \mathrm{a}$ & $236.0 \pm 60.0 \mathrm{~b}$ & $131.2 \pm 19.2 \mathrm{c}$ & $196.3 \pm 53.3 b$ & $311.8 \pm 64.4 \mathrm{a}$ & $254.1 \pm 89.9$ & Soap, lemon, green, fat \\
\hline$\beta$-ionone & $22.6 \pm 5.3 \mathrm{a}$ & $19.1 \pm 3.9 \mathrm{~b}$ & $17.6 \pm 4.2 \mathrm{c}$ & $9.9 \pm 0.6 b$ & $29.6 \pm 1.7 \mathrm{a}$ & $19.7 \pm 4.3$ & Ripe tomato \\
\hline 6-methyl-5-hepten-2-one & $377.0 \pm 86.5 \mathrm{a}$ & $90.9 \pm 39.2 c$ & $145.4 \pm 28.8 \mathrm{~b}$ & $30.6 \pm 15.8 b$ & $378.3 \pm 94.0 \mathrm{a}$ & $204.4 \pm 107.5$ & Sweet, nutty, raspberry \\
\hline Methyl salicylate & $31.4 \pm 3.7 b$ & $15.6 \pm 1.4 \mathrm{c}$ & $72.2 \pm 5.1 \mathrm{a}$ & $48.8 \pm 12.2 \mathrm{a}$ & $32.7 \pm 8.6 b$ & $39.7 \pm 10.7$ & Wintergreen \\
\hline
\end{tabular}


A
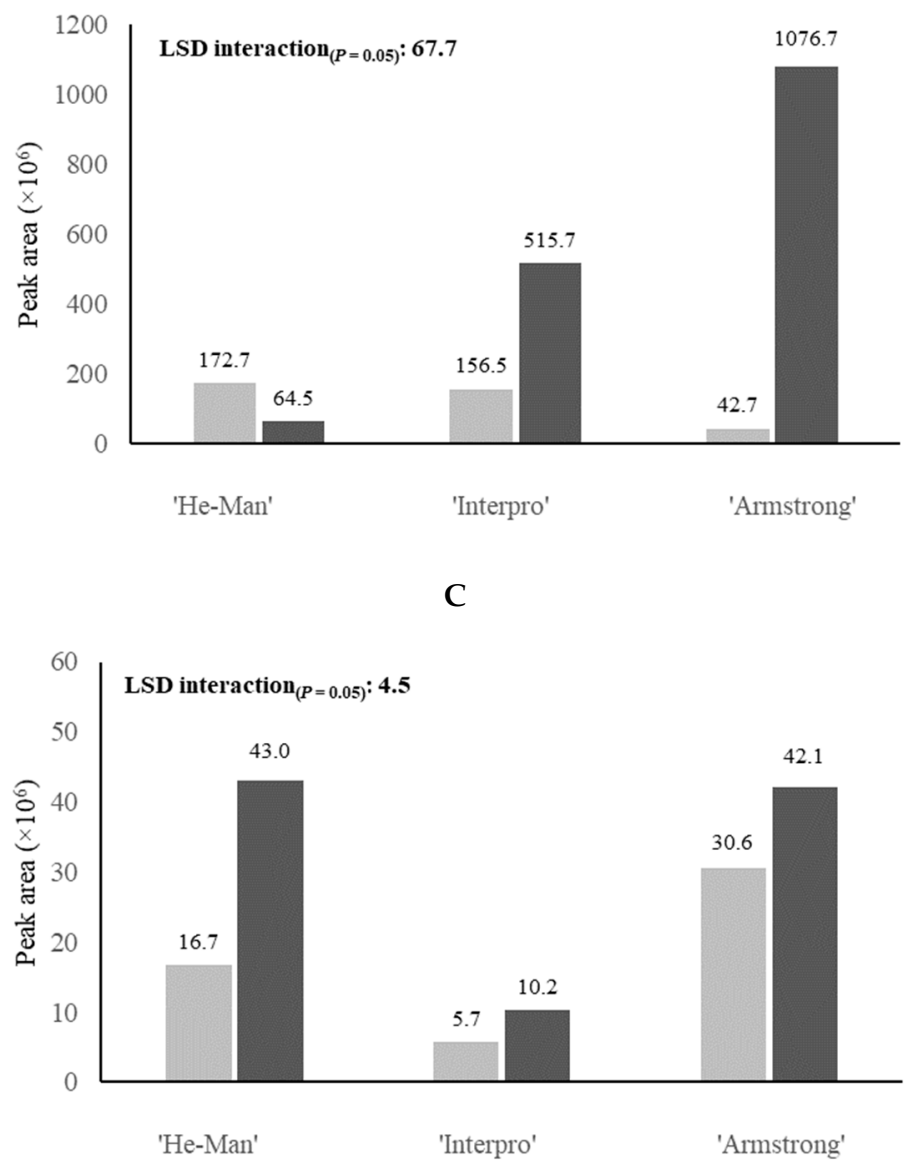

B

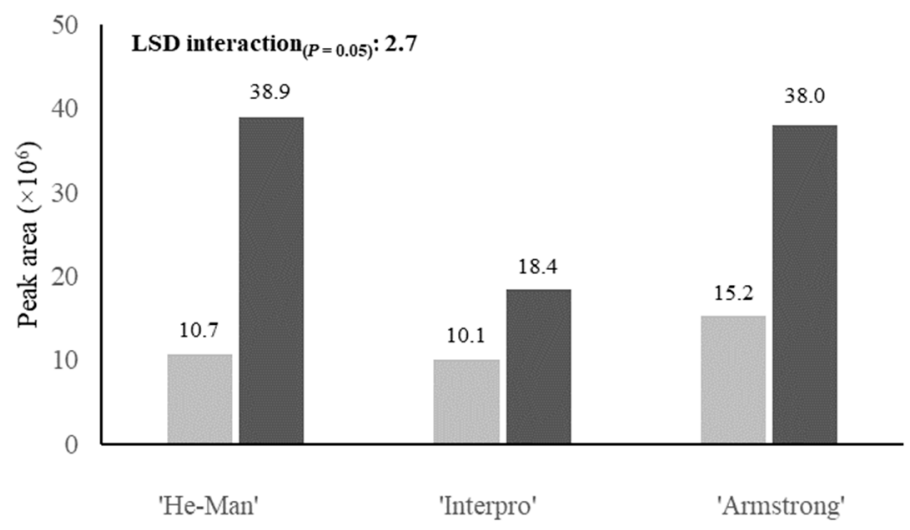

D

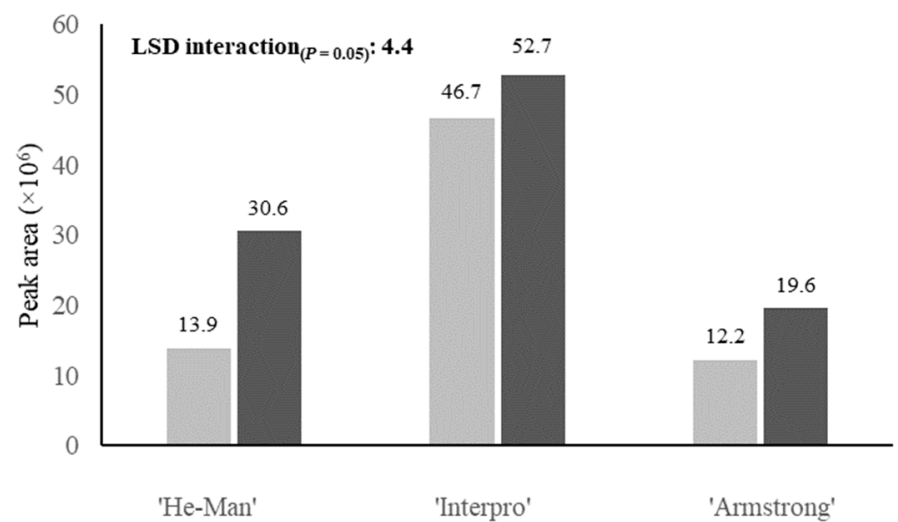

Figure 1. Peak area $\left(\times 10^{6}\right)$ of 3-methyl-1-butanol (A), 1-pentanol (B), 1-hexanol (C), and 3-hexen-1-ol (D) in tomatoes "Sir Elyan" as affected by 'rootstock $\times$ ripening stage' interaction. Light bars: $S_{1}$. Dark bars: $S_{2}$. 
A

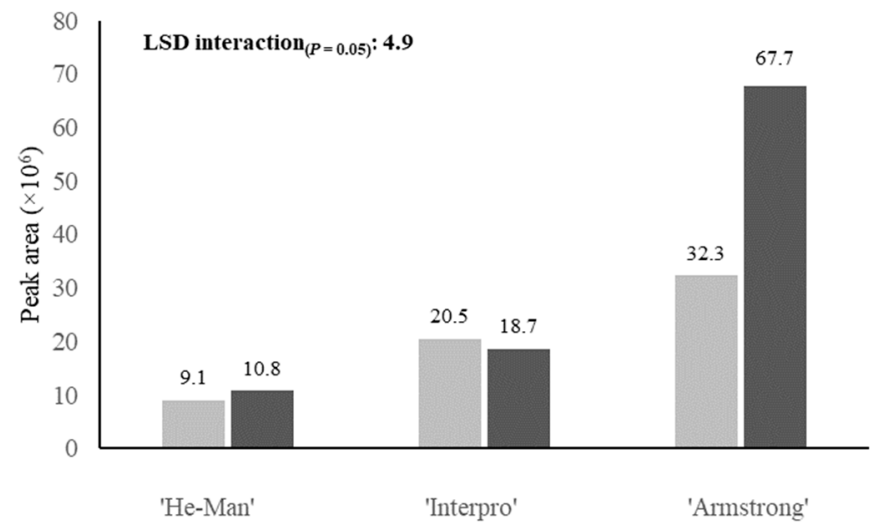

C

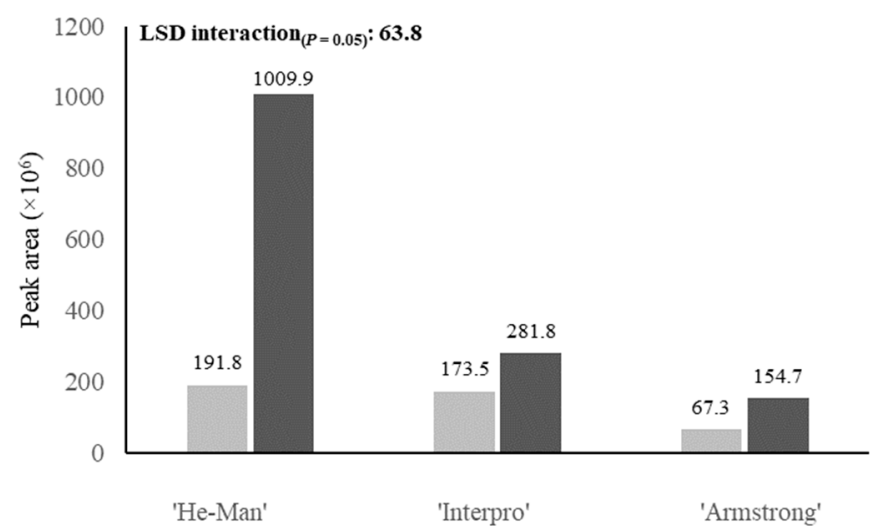

B

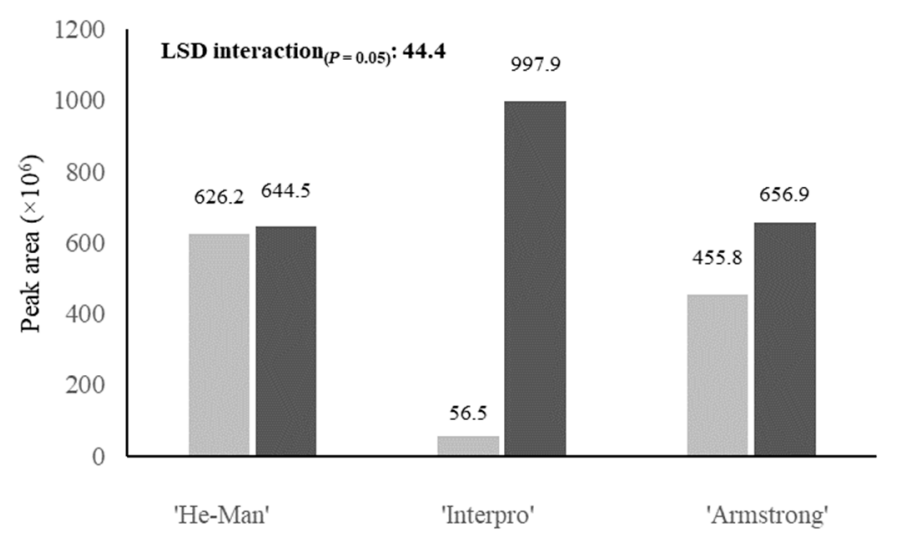

D

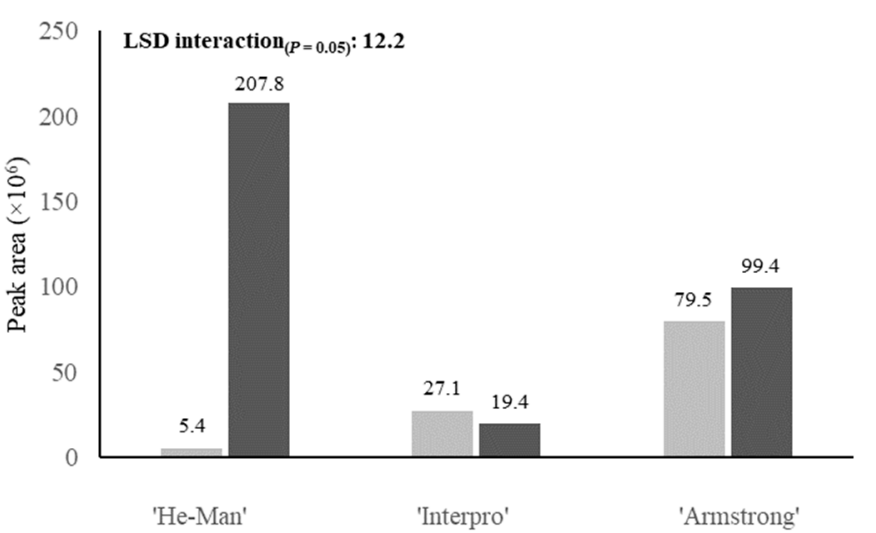

Figure 2. Peak area $\left(\times 10^{6}\right)$ of 3-methylbutanal (A), hexanal (B), E-2-hexenal (C), and E-2-heptenal (D) in tomatoes "Sir Elyan" as affected by 'rootstock $\times$ ripening stage' interaction. Light bars: $S_{1}$. Dark bars: $S_{2}$. 
A

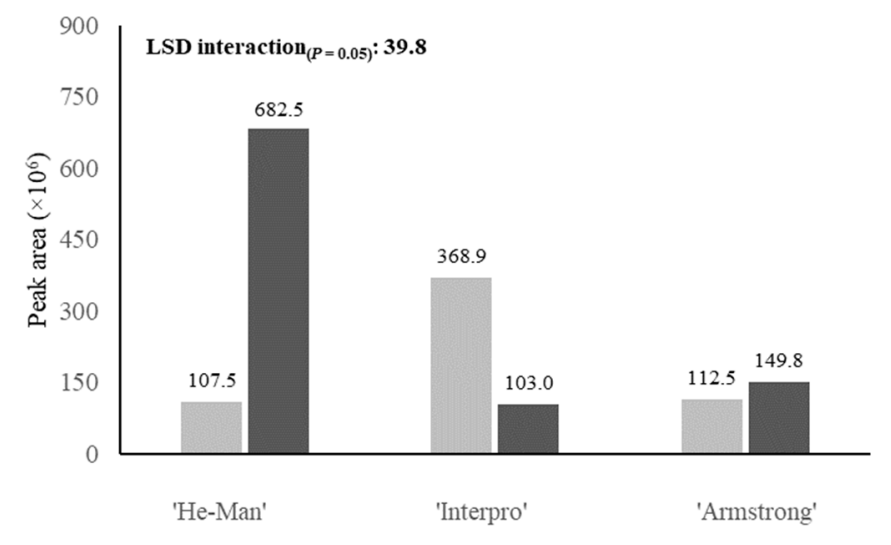

C

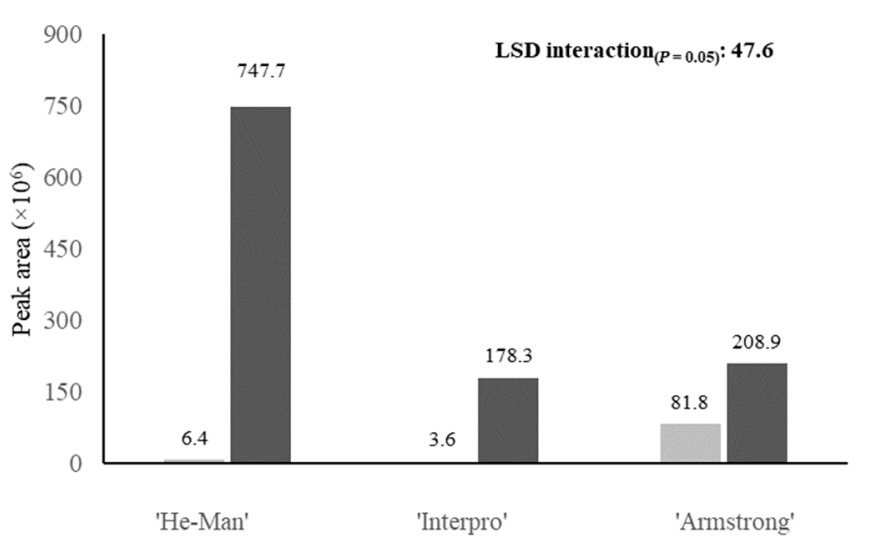

B

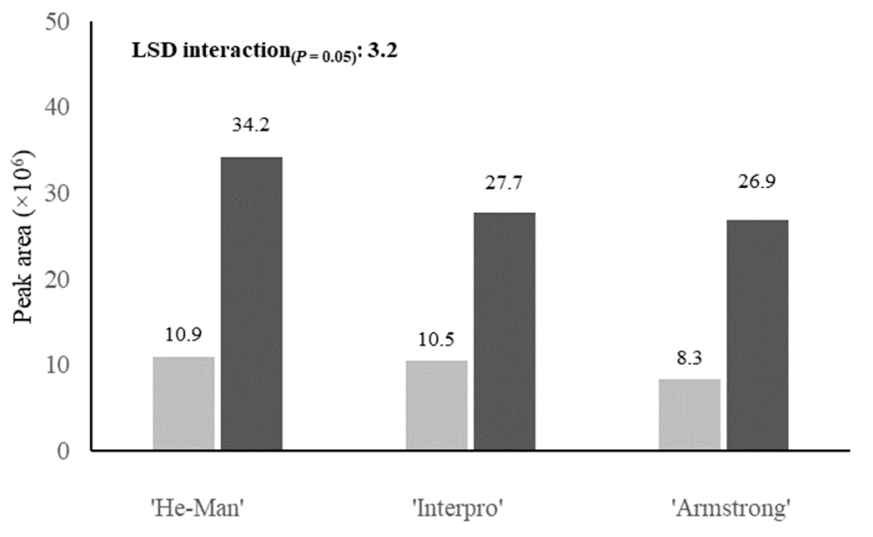

D

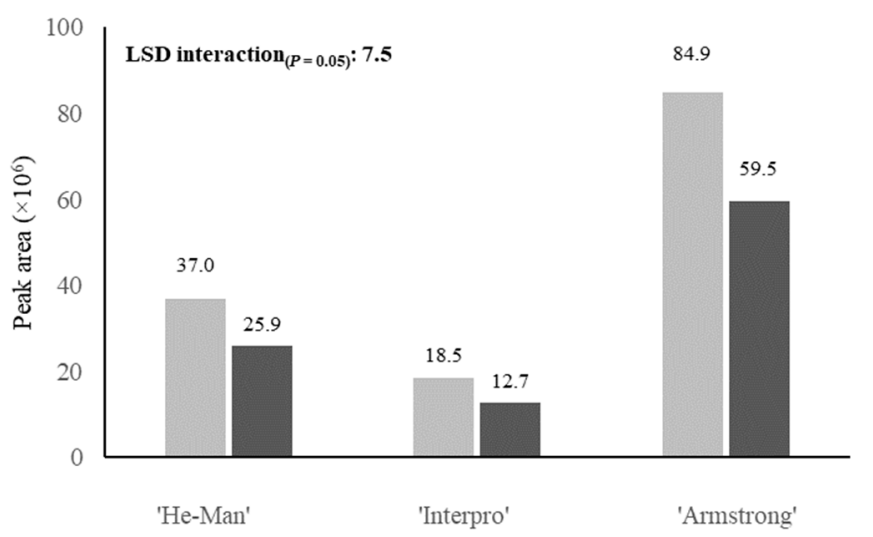

Figure 3. Peak area $\left(\times 10^{6}\right)$ of octanal (A), $\beta$-ionone (B), 6-methyl-5-hepten-2-one $(\mathbf{C})$, and methyl salicylate (D) in tomatoes "Sir Elyan" as affected by 'rootstock $\times$ ripening stage' interaction. Light bars: $S_{1}$. Dark bars: $S_{2}$. 


\subsection{Sensory Analysis}

Tomato samples significantly differed for 11 out the 16 sensory attributes (Table 6). In particular, the bitter perception decreased in the $\mathrm{S}_{2}$ fruits only in the grafting combinations "Sir Elyan"|"Armstrong" $(-21.3 \%)$; the crunchy decreased in the $S_{2}$ fruits of "Sir Elyan" grafted onto "He-Man" and "Interpro" with a trend particularly evident in the latter $(-32.6 \%)$. Both firmness and freshness in general dropped in the $\mathrm{S}_{2}$ fruits, particularly in "Sir Elyan" grafted onto "Interpro" ( $-19.2 \%$ and $-6.0 \%$, respectively). Similarly, herbaceous flavor and odor showed a general decrease in the $S_{2}$ fruits with the strongest reduction in tomato grafted onto "He-Man" (-15.6\% and $-18.2 \%$, respectively). Overall, salt and sour perceptions were higher in the $S_{1}$ fruits as compared to the $S_{2}$ ones, with the highest differences recorded in "Sir Elyan" grafted onto "Interpro" (+34.4\%) and "Armstrong" (+13.8\%), respectively. Differently, the sweet perception showed a different trend passing from $S_{1}$ to $S_{2}$ stage in the rootstock treatments. This sensory attribute increased using "He-Man" (+13.1\%) and "Armstrong $(+12.3 \%)$ rootstocks and decreased in "Interpro". Tomato flavor and odor generally peaked in the $\mathrm{S}_{2}$ fruits, with a gradient recorded in the grafting combinations "Sir Elyan"/"Armstrong" (+18.8\%) and "Sir Elyan"/“Interpro" (+24.5\%).

Table 6. Mean scores of 16 sensory attributes of tomatoes "Sir Elyan" differing for rootstock and ripening stage. Different letters within each row indicate significance at Mann-Whitney's U-test $(p=0.04885)$.

\begin{tabular}{|c|c|c|c|c|c|c|}
\hline Attribute & "He-Man" & "Interpro" & "Armstrong" & "He-Man" & "Interpro" & "Armstrong" \\
\hline Freshness & $7.36 \mathrm{ab}$ & $7.54 \mathrm{a}$ & $7.63 \mathrm{a}$ & $7.00 \mathrm{~b}$ & $7.09 \mathrm{~b}$ & $7.27 \mathrm{~b}$ \\
\hline Firmness & $7.54 \mathrm{ab}$ & $8.09 \mathrm{a}$ & $7.90 \mathrm{a}$ & $6.36 \mathrm{c}$ & $6.54 \mathrm{bc}$ & $7.00 \mathrm{~b}$ \\
\hline Tomato odor & $5.18 \mathrm{~d}$ & $5.54 \mathrm{~cd}$ & $5.81 \mathrm{c}$ & $6.27 \mathrm{~b}$ & $6.90 \mathrm{a}$ & $6.54 \mathrm{~b}$ \\
\hline Herbaceous odor & $5.55 \mathrm{a}$ & $5.63 \mathrm{a}$ & $5.36 \mathrm{a}$ & $4.54 \mathrm{~b}$ & $4.81 \mathrm{~b}$ & $4.54 \mathrm{~b}$ \\
\hline Sour & $3.45 \mathrm{ab}$ & $3.18 \mathrm{~b}$ & $3.72 \mathrm{a}$ & $3.36 \mathrm{~b}$ & $3.00 \mathrm{c}$ & $3.27 \mathrm{~b}$ \\
\hline Sweet & $4.90 \mathrm{c}$ & $5.36 \mathrm{a}$ & $4.45 \mathrm{~d}$ & $5.54 \mathrm{a}$ & $5.19 \mathrm{~b}$ & $5.00 \mathrm{c}$ \\
\hline Bitter & $1.81 \mathrm{~b}$ & $2.09 \mathrm{~b}$ & $2.54 \mathrm{a}$ & $2.09 \mathrm{~b}$ & $2.09 \mathrm{~b}$ & $2.00 \mathrm{~b}$ \\
\hline Crunchy & $6.18 \mathrm{a}$ & $7.00 \mathrm{a}$ & $6.36 \mathrm{ab}$ & $6.09 \mathrm{~b}$ & $4.72 \mathrm{c}$ & $5.54 \mathrm{bc}$ \\
\hline Juicy & $7.09 \mathrm{a}$ & $7.45 \mathrm{a}$ & $7.27 \mathrm{a}$ & $7.27 \mathrm{a}$ & $7.54 \mathrm{a}$ & $7.18 \mathrm{a}$ \\
\hline Herbaceous flavor & $5.27 \mathrm{a}$ & $5.18 \mathrm{a}$ & $5.18 \mathrm{a}$ & $4.45 \mathrm{~b}$ & $4.45 \mathrm{~b}$ & $4.63 \mathrm{~b}$ \\
\hline Off-flavor & $1.18 \mathrm{a}$ & $1.63 \mathrm{a}$ & $1.18 \mathrm{a}$ & $1.36 \mathrm{a}$ & $1.90 \mathrm{a}$ & $1.27 \mathrm{a}$ \\
\hline
\end{tabular}

\subsection{Correlation among Volatiles Concentration and Sensory Scores}

Globally, 132 correlations were analyzed, of which 60 (45\% of total) showed significance, revealing 37 negative and 23 positive relationships (Table 7). In the case of the alcohol volatiles, 17 out of 44 correlations (39\% of total) were significant, whereas they were 26 out of $55(47 \%)$ for the aldehydes and 22 out $33(67 \%)$ for the remaining volatiles. Among the negative correlations, the lowest r-values were recorded among $\beta$-ionone concentration, herbaceous flavor $\left(-0.961^{* * *}\right)$, firmness $\left(-0.946^{* * *}\right)$ and herbaceous odor $\left(-0.932^{* * *}\right)$, followed by that between hexanal concentration and crunchy $\left(-0.929^{* * *}\right)$ (Table 7). Differently, the strongest relationship in the data frame of positive correlations was found between 6-methyl-5-hepten-2-one concentration and tomato flavor $\left(0.873^{* * *}\right), \beta$-ionone and tomato flavor $\left(0.834^{* * *}\right)$, methyl salicylate and sour $\left(0.813^{* * *}\right)$ and among $\beta$-ionone and sweet $\left(0.798^{* * *}\right)$ (Table 7). 
Table 7. Pearson's product-moment correlation coefficients (r) among volatiles concentration and sensory attributes. ${ }^{*}, * *$ and ${ }^{* * *}$ indicate significance at $p \leq 0.05,0.01$ and 0.001 , respectively. NS: not significant.

\begin{tabular}{|c|c|c|c|c|c|c|c|c|c|c|c|c|}
\hline Attribute & $\begin{array}{l}\text { 3-methyl- } \\
\text { 1-butanol }\end{array}$ & 1-pentanol & 1-hexanol & 3-hexen-1-ol & 3-methylbutanal & Hexanal & E-2-hexenal & E-2-heptenal & Octanal & $\beta$-ionone & $\begin{array}{l}\text { 6-methyl-5- } \\
\text { hepten-2-one }\end{array}$ & $\begin{array}{c}\text { Methyl } \\
\text { Salicylate }\end{array}$ \\
\hline Bitter & NS & NS & NS & NS & NS & NS & NS & NS & NS & NS & NS & 0.579 * \\
\hline Crunchy & -0.583 * & NS & NS & NS & NS & $-0.929^{* * * *}$ & NS & NS & NS & $-0.623 * *$ & NS & NS \\
\hline Firmness & NS & $-0.716^{* * *}$ & NS & NS & NS & $-0.788^{* * *}$ & $-0.695^{* *}$ & $-0.524 *$ & NS & $-0.946^{* * * *}$ & $-0.768^{* * *}$ & NS \\
\hline Freshness & NS & $-0.644^{* *}$ & NS & NS & NS & $-0.709^{* * *}$ & $-0.742^{* * *}$ & NS & NS & $-0.922 * * *$ & $-0.747 * * *$ & 0.551 * \\
\hline $\begin{array}{l}\text { Herbaceous } \\
\text { flavor }\end{array}$ & $-0.478^{*}$ & $-0.760^{* * *}$ & NS & NS & NS & $-0.663^{* *}$ & -0.600 ** & -0.539 * & NS & $-0.961^{* * *}$ & $-0.727^{* * *}$ & NS \\
\hline Herbaceous odor & $-0.556^{*}$ & $-0.916^{* * *}$ & $-0.683^{* *}$ & NS & NS & $-0.627^{* *}$ & -0.553 * & $-0.672 * *$ & NS & $-0.932 * * *$ & $-0.749^{* * *}$ & NS \\
\hline Salt & NS & NS & NS & NS & $0.511 *$ & -0.706 ** & $-0.724 * * *$ & NS & NS & $-0.723 * * *$ & $-0.668^{* *}$ & $0.568 *$ \\
\hline Sour & -0.484 * & NS & NS & $-0.854^{* * *}$ & NS & NS & NS & NS & NS & -0.490 * & NS & $0.813^{* * * *}$ \\
\hline Sweet & NS & 0.470 * & NS & $0.656 * *$ & NS & NS & $0.752 * * *$ & NS & $0.628^{* *}$ & $0.798^{* * *}$ & $0.662 * *$ & $-0.827 * * *$ \\
\hline Tomato flavor & $0.522 *$ & $0.875^{* * * *}$ & 0.558 * & NS & NS & NS & $0.607^{* *}$ & $0.656^{* *}$ & $0.580 *$ & $0.834^{* * *}$ & $0.703^{* *}$ & NS \\
\hline Tomato odor & $0.586 *$ & $0.605^{* *}$ & NS & NS & NS & $0.659 * *$ & NS & NS & NS & $0.788 * * *$ & NS & NS \\
\hline
\end{tabular}




\section{Discussion}

Under the specific conditions of our experiment, the $S_{1}$ fruits showed a higher dry matter content, consistent with their higher firmness, this last feature indicating less advanced metabolic processes when the reference ripening stage was achieved. Indeed, the decline in fruit firmness coincides with the up-regulation of several cell wall degrading enzymes, as well as with the dissolution of the middle lamella, leading to the reduction of the intercellular adhesion and cell wall depolymerization [26]. The grafting combination "Sir Elyan"/“"He-Man" yielded the fruits with the highest firmness in both harvest stages, indicating the possibility to influence this trait by selecting the most suitable rootstock. This is an important commercial modification brought by grafting, since textural properties are implicated in fruits' shelf life and transportability, as well as on the perception of their flavor profile [10].

Soluble sugars (mainly glucose, fructose and sucrose) and organic acids (mainly citric and malic) are primary compounds of tomato fruits, whose amount are commonly measured through the soluble solid content (SSC) and titratable acidity (TA), respectively. From a sensorial viewpoint, their measure is linked to the perceived sweetness (SCC) and sourness (TA) of tomatoes, whereas the SCC/TA ratio describes the overall balance among them in the perceived taste [27]. All these variables are reputed primary contributors to the perceived flavor of tomato fruits [27]. In our experiment, the $S_{1}$ fruits were characterized by a decreased SSC and an increased TA, overall indicating their less sweet, more acidic taste. So our results confirm the lower sugar content characterizing tomato fruits harvested at earlier ripening stages [28]. Moreover, our results agree with previous reports of a TA increase up to breaker stage, and its subsequent decline with further ripening [29].

It is generally accepted that vigorous rootstocks show a higher sink strength, competing with the fruits for photosynthates accumulation [30]. Accordingly, we recorded a higher SCC/TA ratio when "Sir Elyan" was grafted onto "He-Man" (i.e., the least vigorous rootstock) than onto "Armstrong" (the most vigorous one), indicating a modified tendency of the fruits to accumulate sugars on the basis of the rootstock vigor.

When compared to other fruits, tomato shows only moderate ascorbic acid (AsA) content, but its dietary importance implies that even small variations in this micronutrient can have relevant effects for consumers [31]. The ascorbic acid concentration we recorded showed a tendency to peak in $S_{1}$ fruits. This is consistent with previous findings about the higher AsA biosynthetic capacity of younger fruits (up to 1.4-fold higher), probably to support their higher rates of cell division and expansion [31]. Indeed, it has been reported that AsA plays an important role in plants, related to cell division and cell wall synthesis [26]. On the other hand, the AsA drop in the $S_{2}$ fruits mirrored the decrease in fruit dry matter content, indicating a prevailing ripening-driven dilution effect in "Sir Elyan" tomatoes. For this nutritional trait, the rootstock-related differences proved to be significant only in the $S_{1}$ fruits, with the grafting combination "Sir Elyan"/“He-Man" (i.e., the least vigorous one) showing the highest concentration. Accordingly, the lowest fruit AsA content characterizing the most vigorous grafting combinations has been explained through their higher vegetative biomass, resulting in a redistribution or accumulation of this molecule in other plant fractions [32].

From a nutraceutical viewpoint, tomato is recognized as one of most important suppliers of carotenoids and phenolic acids, whose content contributes to the antioxidant capacity of this vegetable [33], and the shift in their concentration during ripening is one of the major changes accompanying the improvement of fruit palatability. The $S_{1}$ fruits showed compositional evidences of backwarded ripening process compared to the $S_{2}$ ones, resulting from a higher antioxidant activity and a lower concentration of the main carotenoids. These results agree with previous observations about the pivotal role of ripening stage in influencing these important nutraceutical traits of tomato [34]. Indeed, regarding the main tomato pigments, the carotenogenesis flows from the degradation of the photosynthetic membranes and metabolization of chlorophylls, leading to a progressive accumulation in tomato fruits of the C40 isoprenoids lycopene and $\beta$-carotene [35]. Regarding the rootstock effect, when grafted onto "He-Man", "Sir Elyan" fruits showed the best nutraceutical profile, both in terms of lycopene, $\beta$-carotene, and antioxidant capacity, irrespective of the ripening stage. This is an important 
outcome of our experiment, demonstrating the possibility of an overall functional improvement of greenhouse tomatoes using an appropriate graft combination, also in the light of their usually poorer nutraceutical composition when compared to field-grown tomatoes [36].

As regards the aroma components, excepting methyl salicylate, the $S_{1}$ fruits showed the lowest content for all the detected volatiles. The most severe reductions regarded the carotenoid-derived 6-methyl-5-hepten-2-one and $\beta$-ionone $(-92 \%$ and $-67 \%$, respectively), the lignin-related 3-methyl-1-butanol (-78\%) and the lipid-derived E-2-hexenal and E-2-heptenal $(-70 \%$ and $-66 \%$, respectively). Consistent with the findings of Raffo et al. [28], such reductions clearly indicate a disturbance in the formation of tomato key odorants induced by early harvests. Indeed, it is known that the ability of tomatoes to form lipid-derived volatiles increases as the fruits ripen [37], so the reduced concentration we recorded in $\mathrm{S}_{1}$ fruits in terms of $\mathrm{C} 6$ aldehydes and related alcohols (namely 1-hexanol and 3-hexen-1-ol) probably reflects the developmentally-induced lower expression of genes encoding for lipoxygenases and hydroperoxide lyases converting unsaturated fatty acids to 13-hydroperoxides and then to $\mathrm{C} 6$ aldehydes [38]. On the other hand, the increase in 6-methyl-5-hepten-2-one and $\beta$-ionone we found in the $S_{2}$ fruits, is consistent with their higher concentration of precursors lycopene and $\beta$-carotene, respectively [39]. On the contrary, methyl salicylate is typically associated to anti-herbivores defense of plant tissues [40], hence the higher concentration of this last volatile clearly indicates a less advanced ripening process in $\mathrm{S}_{1}$ fruits, whose compositional traits still refer to the seed-protecting role of the pericarp. From a sensory viewpoint, the $S_{1}$ fruits were characterized as firmer and with the highest freshness, herbaceous odor and flavor. Differently, the $S_{2}$ fruits were generally scored as less acidic and with stronger typical tomato odor and flavor. Such modifications were clearly distinguishable, despite in the latter fruits a significant increase was recorded in "green" and "grassy" volatiles such as hexanal, E-2-hexenal, octanal, 3-hexen-1-ol, or 1-pentanol. This finding is only apparently contradictory, since in tomato no single compound has been found to be reminiscent of fresh ripe tomatoes, whose aroma, instead, springs from a multitude of several volatiles, blended in appropriate concentrations [41]. In this view, the correlation analysis revealed that 1-pentanol, $\beta$-ionone, and 6-methyl-5-hepten-2-one gave the strongest contribution to tomato flavor perception, whereas $\beta$-ionone and hexanal were the volatiles most tightly linked to the increased tomato odor perception. On the other hand, the alcohol 1-pentanol, the aldehydes hexanal and E-2-hexenal, as well as the apocarotenoid $\beta$-ionone and 6-methyl-5-hepten-2-one displayed a pool of negative correlations with some traits typically associated to less ripe tomatoes (namely crunchy, firmness, freshness, and herbaceous flavor), highlighting their primary role in accompanying the organoleptic evolution of tomatoes during ripening. It is interesting to note that, consistent with its higher concentration in unripe fruits, methyl salicylate was positively correlated to the perceived sour, salt and bitter, so suggesting a possible interactive effect of this compositional trait in generating these peculiar perceptions in less ripe "Sir Elyan" fruits. As regards the studied rootstocks, the volatile composition was somewhat erratic and unpredictable on the basis of the rootstock characteristics. Irrespective of the harvest stage, the grafting combination "Sir Elyan"/"He-Man" gave the highest concentration for 6 out of the 12 volatiles detected (including the fruity volatiles $\beta$-ionone and 6-methyl-5-hepten-2-one), whereas the combinations "Sir Elyan"|"Armstrong" gave the highest concentration for 5 volatiles (including 1-pentanol, 1-hexanol and methyl salicylate, all associated to "green" notes). Only 3-hexen-1-ol showed the highest concentration when "Sir Elyan" was grafted onto "Interpro". Such diversity gave a different ability to the rootstocks to offset the fruit sensory modifications brought by the different harvest stages. Indeed, when grafted onto "He-Man" or "Interpro", "Sir Elyan" gave $\mathrm{S}_{1}$ fruits characterized by an attenuated bitter perception, consistent with their lower concentration of methyl salicylate. Moreover, the grafting combination "Sir Elyan"/“Interpro" gave less acidic $\mathrm{S}_{1}$ fruits, characterized also by improved sweetness and tomato flavor. Differently, "He-Man" and "Armstrong" were able to accentuate the perception of sweet, sour and typical tomato flavor in the $S_{2}$ fruits, which, despite a lower SSC, mirrored their higher 6-methyl-5-hepten-2-one content when compared to "Interpro". 
This finding is consistent with the widely accepted idea that some fruity/floral volatiles improve the perception of sweetness in tomato fruits [24].

\section{Conclusions}

Our findings indicate that the harvest stage significantly affected both nutraceutical and eating quality profile of "Sir Elyan" tomatoes, but a certain dichotomy emerged among the functional profile and some sensorial traits in "Sir Elyan" fruits, in relation to their harvest stage. On the other hand, the rootstock genotype influenced both the nutraceutical and quality traits of the fruits. Despite none of the studied rootstocks was able to improve all the quality traits considered in this experiment, our results suggest the possibility to selectively improve the nutraceutical or sensorial profile of "Sir Elyan" fruits by selecting the most appropriated rootstock, provided that its interactive effects with the harvest stage are taken into account.

Author Contributions: Conceptualization, G.M., F.G., C.L.; methodology, V.R., R.P.M.; formal analysis, V.R., A.M., M.D.; investigation, A.M., M.D.; data curation, L.S., R.P.M.; writing—original draft preparation, R.P.M., F.G., V.R.; writing-review and editing, C.L., G.M., L.S.; supervision, F.G. All authors have read and agreed to the published version of the manuscript.

Funding: This research received no external funding.

Conflicts of Interest: The authors declare no conflict of interest.

\section{References}

1. Mauro, R.P.; Lo Monaco, A.; Lombardo, S.; Restuccia, A.; Mauromicale, G. Eradication of Orobanche/Phelipanche spp. seedbank by soil solarization and organic supplementation. Sci. Hortic. 2015, 193, 62-68. [CrossRef]

2. Mauro, R.P.; Agnello, M.; Rizzo, V.; Graziani, G.; Fogliano, V.; Leonardi, C.; Giuffrida, F. Recovery of eggplant field waste as a source of phytochemicals. Sci. Hortic. 2020, 261, 109023. [CrossRef]

3. Sabatino, L.; D'Anna, F.; Iapichino, G.; Moncada, A.; D'Anna, E.; De Pasquale, C. Interactive effects of genotype and molybdenum supply on yield and overall fruit quality of tomato. Front. Plant Sci. 2019, 9, 1922. [CrossRef]

4. Raiola, A.; Rigano, M.M.; Calafiore, R.; Frusciante, L.; Barone, A. Enhancing the health-promoting effects of tomato fruit for biofortified food. Mediat. Inflamm. 2014, 2014, 1-16. [CrossRef]

5. Tieman, D.; Zhu, G.; Resende, M.F.R.; Lin, T.; Nguyen, C.; Bies, D.; Rambla, J.L.; Beltran, K.S.O.; Taylor, M.; Zhang, B.; et al. A chemical genetic roadmap to improved tomato flavor. Science 2017, 355, 391-394. [CrossRef]

6. Wang, L.; Baldwin, E.A.; Bai, J. Recent Advance in Aromatic Volatile Research in Tomato Fruit: The Metabolisms and Regulations. Food Bioprocess Technol. 2016, 9, 203-216. [CrossRef]

7. Rouphael, Y.; Kyriacou, M.C.; Colla, G. Vegetable grafting: A toolbox for securing yield stability under multiple stress conditions. Front. Plant Sci. 2018, 8, 10-13. [CrossRef]

8. Allevato, E.; Mauro, R.P.; Stazi, S.R.; Marabottini, R.; Leonardi, C.; Ierna, A.; Giuffrida, F. Arsenic accumulation in grafted melon plants: Role of rootstock in modulating root-to-shoot translocation and physiological response. Agronomy 2019, 9, 828. [CrossRef]

9. Mauro, R.P.; Agnello, M.; Distefano, M.; Sabatino, L.; Alberto, S.B.P.; Leonardi, C.; Giuffrida, F. Chlorophyll fluorescence, photosynthesis and growth of tomato plants as affected by long-term oxygen root zone deprivation and grafting. Agronomy 2020, 10, 137. [CrossRef]

10. Kyriacou, M.C.; Rouphael, Y.; Colla, G.; Zrenner, R.; Schwarz, D. Vegetable grafting: The implications of a growing agronomic imperative for vegetable fruit quality and nutritive value. Front. Plant Sci. 2017, 8, 1-23. [CrossRef]

11. Wang, D.; Seymour, G.B. Tomato Flavor: Lost and Found? Mol. Plant 2017, 10, 782-784. [CrossRef]

12. Saltveit, M.E. Fruit ripening and fruit quality. In Tomatoes; CABI Publishing: Wallingford, UK, 2005; pp. $145-170$.

13. Tirelli, D. Richieste del consumatore. In Il Pomodoro; Bayer CropScience: Bologna, Italy, 2010; pp. 548-555.

14. Sharma, S.K.; Le Maguer, M. Lycopene in tomatoes and tomato pulp fractions. Ital. J. Food Sci. 1996, 8, 107-113. 
15. Gregory, G.K.; Chen, T.-S.; Philip, T. Quantitative analysis of carotenoids and carotenoid esters in fruits by HPLC: Red bell peppers. J. Food Sci. 1987, 52, 1071-1073. [CrossRef]

16. Subagio, A.; Morita, N.; Sawada, S. Carotenoids and their fatty-acid esters in banana peel. J. Nutr. Sci. Vitaminol. 1996, 42, 553-566. [CrossRef]

17. Nisperos-Carriedo, M.O.; Buslig, B.S.; Shaw, P.E. Simultaneous detection of dehydroascorbic, ascorbic, and some organic acids in fruits and vegetables by HPLC. J. Agric. Food Chem. 1992, 40, 1127-1130. [CrossRef]

18. Brand-Williams, W.; Cuvelier, M.E.; Berset, C. Use of a free radical method to evaluate antioxidant activity. Food Sci. Technol. 2007, 28, 25-30. [CrossRef]

19. Beltran, J.; Serrano, E.; López, F.J.; Peruga, A.; Valcarcel, M.; Rosello, S. Comparison of two quantitative GC-MS methods for analysis of tomato aroma based on purge-and-trap and on solid-phase microextraction. Anal. Bioanal. Chem. 2006, 385, 1255-1264. [CrossRef]

20. UNI EN ISO 13299. Sensory Analysis-Methodology-General Guidance for Establishing A Sensory Profile; Ente Nazionale Italiano di Unificazione: Milano, Italy, 2016.

21. ISO 8586. Sensory Analysis—General Guidelines for the Selection, Training and Monitoring of Selected Assessors and Expert Sensory Assessors; International Organization for Standardization: Geneva, Switzerland, 2012.

22. UNI EN ISO 8589. Analisi Sensoriale—Guida Generale per la Progettazione di Locali di Prova; Ente Nazionale Italiano di Unificazione: Milano, Italy, 2014.

23. Petró-Turza, M. Flavor of tomato and tomato products. Food Rev. Int. 1986, 2, 309-351. [CrossRef]

24. Baldwin, E.A.; Goodner, K.; Plotto, A. Interaction of volatiles, sugars, and acids on perception of tomato aroma and flavor descriptors. J. Food Sci. 2008, 73, S294-S307. [CrossRef]

25. Viljanen, K.; Lille, M.; Heiniö, R.L.; Buchert, J. Effect of high-pressure processing on volatile composition and odour of cherry tomato purée. Food Chem. 2011, 129, 1759-1765. [CrossRef]

26. Bertin, N.; Génard, M. Tomato quality as influenced by preharvest factors. Sci. Hortic. 2018, 233, $264-276$. [CrossRef]

27. Di Gioia, F.; Serio, F.; Buttaro, D.; Ayala, O.; Santamaria, P. Influence of rootstock on vegetative growth, fruit yield and quality in "Cuore di Bue", an heirloom tomato. J. Hortic. Sci. Biotechnol. 2010, 85, 477-482. [CrossRef]

28. Raffo, A.; Baiamonte, I.; Nardo, N.; Nicoli, S.; Moneta, E.; Peparaio, M.; Sinesio, F.; Paoletti, F. Impact of early harvesting and two cold storage technologies on eating quality of red ripe tomatoes. Eur. Food Res. Technol. 2018, 244, 805-818. [CrossRef]

29. Kader, A.; Stevens, M.A.; Albright-Holton, M.; Morris, L.L.; Algazi, M. Effect of fruit ripeness when picked on flavor and composition in fresh market tomatoes. J. Am. Soc. Hortic. Sci. 1977, 52, 1071-1073.

30. Oztekin, G.B.; Giuffrida, F.; Tuzel, Y.; Leonardi, C. Is the vigour of grafted tomato plants related to root characteristics? J. Food Agric. Environ. 2009, 7, 364-368.

31. Mellidou, I.; Keulemans, J.; Kanellis, A.K.; Davey, M.W. Regulation of fruit ascorbic acid concentrations during ripening in high and low vitamin C tomato cultivars. BMC Plant Biol. 2012, 12, 1. [CrossRef]

32. Wadano, A.; Azeta, M.; Itotani, S.I.; Kanda, A.; Iwaki, T.; Taira, T.; Fujii, Y.; Nishiura, Y.; Murase, H.; Honami, N. Change of ascorbic acid level after grafting of tomato seedlings. Zeitschrift Naturforsch 1999, 54, 830-833. [CrossRef]

33. Rizzo, V.; Clifford, M.N.; Brown, J.E.; Siracusa, L.; Muratore, G. Effects of processing on the polyphenol and phenolic acid content and antioxidant capacity of semi-dried cherry tomatoes (Lycopersicon esculentum M.). J. Sci. Food Agric. 2016, 96, 2040-2046. [CrossRef]

34. Raffo, A.; Leonardi, C.; Fogliano, V.; Ambrosino, P.; Salucci, M.; Gennaro, L.; Bugianesi, R.; Giuffrida, F.; Quaglia, G. Nutritional value of cherry tomatoes (Lycopersicon esculentum cv. Naomi F1) harvested at different ripening stages. J. Agric. Food Chem. 2002, 50, 6550-6556. [CrossRef]

35. Fanciullino, A.L.; Bidel, L.P.R.; Urban, L. Carotenoid responses to environmental stimuli: Integrating redox and carbon controls into a fruit model. Plant Cell Environ. 2014, 37, 273-289. [CrossRef]

36. Toor, R.K.; Savage, G.P. Antioxidant activity in different fractions of tomatoes. Food Res. Int. 2005, 38, $487-494$. [CrossRef]

37. Baldwin, E.A.; Nisperos-Carriedo, M.O.; Moshonas, M.G. Quantitative analysis of flavor and other volatiles and for certain constituents of two tomato cultivars during ripening. J. Am. Soc. Hortic. Sci. 1991, 116, 265-269. [CrossRef] 
38. Zhang, B.; Tieman, D.M.; Jiao, C.; Xu, Y.; Chen, K.; Fe, Z.; Giovannoni, J.J.; Klee, H.J. Chilling-induced tomato flavor loss is associated with altered volatile synthesis and transient changes in DNA methylation. Proc. Natl. Acad. Sci. USA 2016, 113, 12580-12585. [CrossRef]

39. Mathieu, S.; Cin, V.D.; Fei, Z.; Li, H.; Bliss, P.; Taylor, M.G.; Klee, H.J.; Tieman, D.M. Flavour compounds in tomato fruits: Identification of loci and potential pathways affecting volatile composition. J. Exp. Bot. 2009, 60, 325-337. [CrossRef]

40. James, D.G.; Price, T.S. Field-testing of methyl salicylate for recruitment and retention of beneficial insects in grapes and hops. J. Chem. Ecol. 2004, 30, 1613-1628. [CrossRef]

41. Baldwin, E.A.; Scott, J.W.; Shewmaker, C.K.; Schuch, W. Flavor trivia and tomato aroma: Biochemistry and possible mechanisms for control of important aroma components. HortScience 2000, 35, 1013-1022. [CrossRef]

(C) 2020 by the authors. Licensee MDPI, Basel, Switzerland. This article is an open access article distributed under the terms and conditions of the Creative Commons Attribution (CC BY) license (http://creativecommons.org/licenses/by/4.0/). 